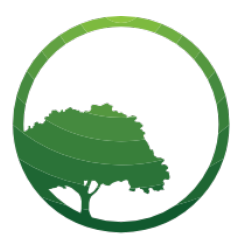

Business \& Social Science IJRBS

\section{Research in Business and Social Science}

IJRBS Vol 8 No 4, ISSN: 2147-4478

Contents available at www.ssbfnet.com/ojs

\title{
Ego-Centric Social Network Analysis in Marketing of Fish From Cage Culture System In Simalungun District, Indonesia
}

\section{Feriel Amelia Sembiring}

Master of Sociology Study Program, Universitas Sumatera Utara, Indonesia

\section{Fikarwin Zuska}

Department of Anthropology, Universitas Sumatera Utara, Indonesia

\section{Bengkel Ginting}

Department of Social Welfare, Universitas Sumatera Utara, Indonesia

\section{Rizabuana Ismail}

Corresponding Author: Master of Sociology Study Program, Universitas Sumatera Utara, Indonesia

\section{Henry Sitorus}

Master of Sociology Study Program, Universitas Sumatera Utara, Indonesia

\begin{abstract}
Aquaculture of Cage Culture is one of the main activities carried out by the community in the village of Haranggaol to fulfill their economic needs. This cultivation business establishes a relationship between traders and cages in terms of marketing their crops. There are 3 egocentric actors in the Haranggaol area. They are collectors (entrepreneurs/farmers who own capital), namely the Rohakinian group, the Siharo group, and the Paimaham group. Through these three egocentric actors, a social network is formed with several alters. Based on the qualitative approach with use Ucinet software, the mapping of their social networks can be seen as follows: alter actors connected to the Rohakinian group are 12 farmers in the group and 2 farmers outside the group with a density of 0.033 . There are 27 alter actors connected to the Siharo group, 21 from the group and 6 from outside the group with a density of 0.014 . There are 27 alter actors connected to the Paimaham group, namely 36 farmers from their groups and 10 farmers outside the group with a density of 0.005 . The social networks that occur between these actors are intertwined due to the existence of kinship relationships, family or close friends who know each other among them. The relationship between family, family or close friends built with mutual trust make this network integrated.
\end{abstract}

Key words: Egocentric; Social Networks;Cage Culture; Social Relationships; Alter; Ego

JEL classification: $Z 13$

Submitted: 02.06.2019 - Accepted: 23.06.2019 


\section{Introduction}

Fisheries are a challenging system to manage due to the mobility and non-excludability of the Resource. Evidence suggests that fisheries have better ecological, social and economic outcomes under a comanagement regime in which responsibility for management is shared between resource users and typically, a government agency (Stevens, Frank, \& Kramer, 2015). Fishery as one sub sector supporting Indonesia's economy also needs to be developed to improve the international trade in Indonesia. Fauzy said revealed that fish is one of the commodities which plays an important role in human life (Rachmawati, Mursinto, \& Istifadah, 2017). Communities in North Sumatra make the profession of fishermen the main source of their livelihood. However, in contrast to the lives of the fishermen in general, the community carries out fishing activities through aquaculture activities. Lake Toba Floating Cage Cultivation (KJA) is an aquaculture conducted in the Lake Toba area of North Sumatra, especially in the suburbs of Lake Toba.

As a cultivating village and producing cage culture in the vicinity of Lake Toba, Haranggaol is an area known for the large number of cage fish production, either carp or tilapia. Data obtained in 2012 from the Simalungun District Fisheries and Animal Husbandry Office showed that the Haranggaol Subdistrict showed that the Haranggaol Subdistrict was the largest producer of community cages when compared to other sub-districts in Simalungun. To be more clear about the details of the number of fisheries households in various subdistricts in Simalungun District in 2012 can be seen in table 1 below:

Table 1: Number of Fisheries Households (RTP), Area, Production and Value Selling of Farmers of Floating and Cage Net

\begin{tabular}{|c|c|c|c|c|c|}
\hline & Sub-district & $\begin{array}{l}\text { Number of } \\
\text { (RTP) }\end{array}$ & Large (Bag) & Production & $\begin{array}{l}\text { Value Selling } \\
\text { (Rp) }\end{array}$ \\
\hline 1. & Pematang Silimahuta & 1 & 6 & 3,6 & 59 \\
\hline 2. & Haranggaol Horison & 280 & 2.991 & $3.964,7$ & 64.941 \\
\hline 3. & Dolok Pardamean & 47 & 190 & 158,8 & 2.601 \\
\hline 4. & Pematang Sidamanik & 36 & 159 & 144,6 & 21.202 \\
\hline 5. & Girsang Sipangan & 94 & 854 & $1.294,6$ & - \\
\hline \multicolumn{2}{|c|}{ District of Simalungun } & 458 & 412 & $5.562,5$ & 88.803 \\
\hline
\end{tabular}

Source: Simalungun District Fisheries and Animal Husbandry Service (2012)

The large amount of production from the harvest of cage culture in the Haranggaol area has caused the fish harvest to be marketed to various regions, including Tanah Karo, Medan, Rantau Prapat and other regions. Many fish products indicate that the number of cages is also confirmed. With a large number of cages that will bring this cultivation business connected between collector traders and cage farmers in launching a cage fish cultivation business, including in terms of marketing their crops or selling their crops.

Fishermen are faced with marketing dependence, namely the marketing mechanism through capital owners. Marketing through capital owners is a strengthened choice through the dependence of social contracts through trust values. The dependence of fishermen on capital owners is a social bond that is a guide to obtaining fulfillment his life. The dependence of fishermen on capital owners is a social bond that is a guide to obtaining their life needs (Triyanti, Yuliaty, \& Apriliani, 2014).

Relationships that have been intertwined intensely occur through how much they have social relations to a broad extent, the closeness relationship and also the relationship to mediation will increasingly support social networks that are among the cage farmers and collecting traders (ego). In seeking information on the 
marketing of cage-yielded fish, cage farmers must build a network structure with other cage farmers to get information on who the collecting traders can help market their fish products to the next marketing agent (wholesalers or retailers). As Gezelius and Rudd (Turner, Polunin, \& Stead, 2014) said that fishers draw on social relationships to acquire information that contributes to decisions about when and where to fish. Such relationships can increase fishing efficiency by reducing time spent searching for productive grounds. Heterogeneity in fishers' decisions about whether to share information, and with whom, mean that different fishers may have access to different information.

Analysis of social networks is an interaction or relationship that is formed because of the network between actors (nodes) that are associated with a line / node (link) where the link indicates the existence of a relationship. Networks view any system as a set of interrelated actors or nodes. Actors can represent entities at various levels of collectivity, such as people, companies, countries, and so on. Bonds between actors can be of various types, such as friendship, competition, etc., and can be characterized by several dimensions, such as duration, frequency, and the like that can be described through a diagram using a social network data processing program (Borgatti, Stephen, \& Li, 2009).

\section{Literature Review}

Social networks are a social structure created by individuals or organizations commonly called nodes that are bound or connected by one or more certain interdependent characteristics between them. Some examples of social networks include friendship, kinship, financial exchange, relationship relationships, sexual relations or relationships of trust, knowledge or prestige (Lawang, 2004).

Social networks are one dimension of social capital besides trust and norms. The central idea of social capital is that social networks are a valuable asset (Field, 2005). Networks provide a basis for social cohesion because they enable people to cooperate and not only with people they know directly for mutual benefits. Social networks are a special type of network, where bonds that connect one point to another are social relations. Seen in this type of bond, then directly or indirectly the members of a social network are human. Social networks representing individual points of view, for example, organization, agency, government or state.

According to Granovetter the relationship (network) occurs based on ideas that actors (individual or collectivities) are in different stratifications so that they have different access to valuable resources (wealth, power, information). The distribution that is unequal from limited resources will lead to both cooperation and competition, in which several groups will join forces to obtain limited resources by collaborating. As a result, in systems where the structure tends to be stratified, certain components will depend on other components (Ritzer \& Goodman, Teori Sosiologi Modern, 2008)

According to Granovetter distinguishes between weak and strong bonds, strong bonds, for example, the connection between people and their close friends and relatives, weak ties, connections between people and their acquaintances. Granovetter explained that weak ties can be very important. Examples of weak ties between two actors can help as a bridge between two groups with strong internal ties, without the existence of two such groups, the two groups might be isolated. This isolation can further cause the social system to become more fragmented. An individual without a weak bond will feel isolated in a group whose ties are very strong and will lack information about what is happening in other groups or the wider community. Although Granovetter stressed the importance of weak ties, he immediately explained that even strong ties have value. For example, people who have strong ties have greater motivation to help each other and be better prepared to help one another.

Whereas based on egocentric networks, two bonds are formed in the network between ego and alter and also alter with alter which are closed networks and open networks. Networks are called open if relations only occur between ego actors and temporary alters between alters not connected. Open networks are also called radical networks. Conversely, if the network is said to be closed if not only ego and alter actors are connected but also alter actors with alter actors. This network is called network locking / interlock (Eriyanto, 2014).

\section{Reseach and Methodology}


Haranggaol is an area located in the area of Lake Toba in Haranggaol Horison Subdistrict, Simalungun District. This area is also the center of floating net cages in the Lake Toba area which are detached from certain parties. To find out, describe and describe in detail the structure and actors The actors involved in marketing the results of this cage are then used a qualitative approach with descriptive methods. Based on the data obtained in the field, three groups of collectors are found who are informants in this paper who are still active in floating net cages business activities which are then explored deeper into the network formed with cage farmers. The three groups of informants were:

\title{
Rohakinian group
}

Rohakinian group is a group managed by Mr. MS (63 years) and now this business is continued by his son named AS. This business has long been carried out by the hundreds of cages that are financed. The network of cages owned by Mr AS is currently quite extensive among fellow cage business owners. in this area.

\section{Siharo group}

The Siharo group is a group managed by a young man named IR (24th). This business belongs to his parents which he has managed since the last two years. The number of cages he has invested in several cage farmers has made him also have a wide net cages.

\section{Paimaham group}

The Paimaham group is a group managed by Mr. SS, he is better known as Bombom. Just like the two groups above, this group also has an extensive floating net cages in the Haranggaol area by having thirteen farmers in their group.

Furthermore, the results of the research obtained through interviews were analyzed using Ucinet software with versus 6.6 , where the results in the form of sociograms then describe the relationships that occur between actors both ego and alter or alter with alter.

\section{Findings of the Study}

\section{Analysis of the Ego Centric Social Network of Cage Culture}

\author{
Ego Actor and Actor Alter
}

The ego network is a network located in one person as the center of the network. Ego network will form a network with alters.Ego collaborates with alter but not necessarily cooperates with alters from other alters (alter with alter) even though they are still in the same network. With the term that establishes such cooperation is between the alter and the permanent alter where the ego is the center of the network. The thing that causes the actor to become an ego in the network of floating net cages in Haranggaol is because the ego is the one who opens floating net cages by carrying out all its functions including giving capital to prospective cage farmers, feed suppliers, and market harvested fish.

The ego actor is a cage entrepreneur, who also takes on the role of a cage farmer and collector at the time of marketing. The role of almost all ego actors is indeed very important in floating net cage activities. cause the ego to be addressed by actors whose roles are outside the role of the ego actor. Meanwhile, the actors who collaborate with the ego especially in the case of floating net cages are called alterations. These alteralters will meet the ego actor to cooperate. But not all alters who join meet the ego but there are also other alter in the ego group.

\section{Analysis of Ego Social Networks in Each Group}

\section{Social Network Analysis AS (Rohakinian)}

At present, the number of cages managed by informants reaches hundreds among fellow business owners, making MS a cage businessman who establishes relationships with several cage fish farmers. At present, the informant has handed over his business to his son named AS. As an ego actor, Mr. MS or his AS child who now holds control of the cage business has actors called alter(Figure 1). 


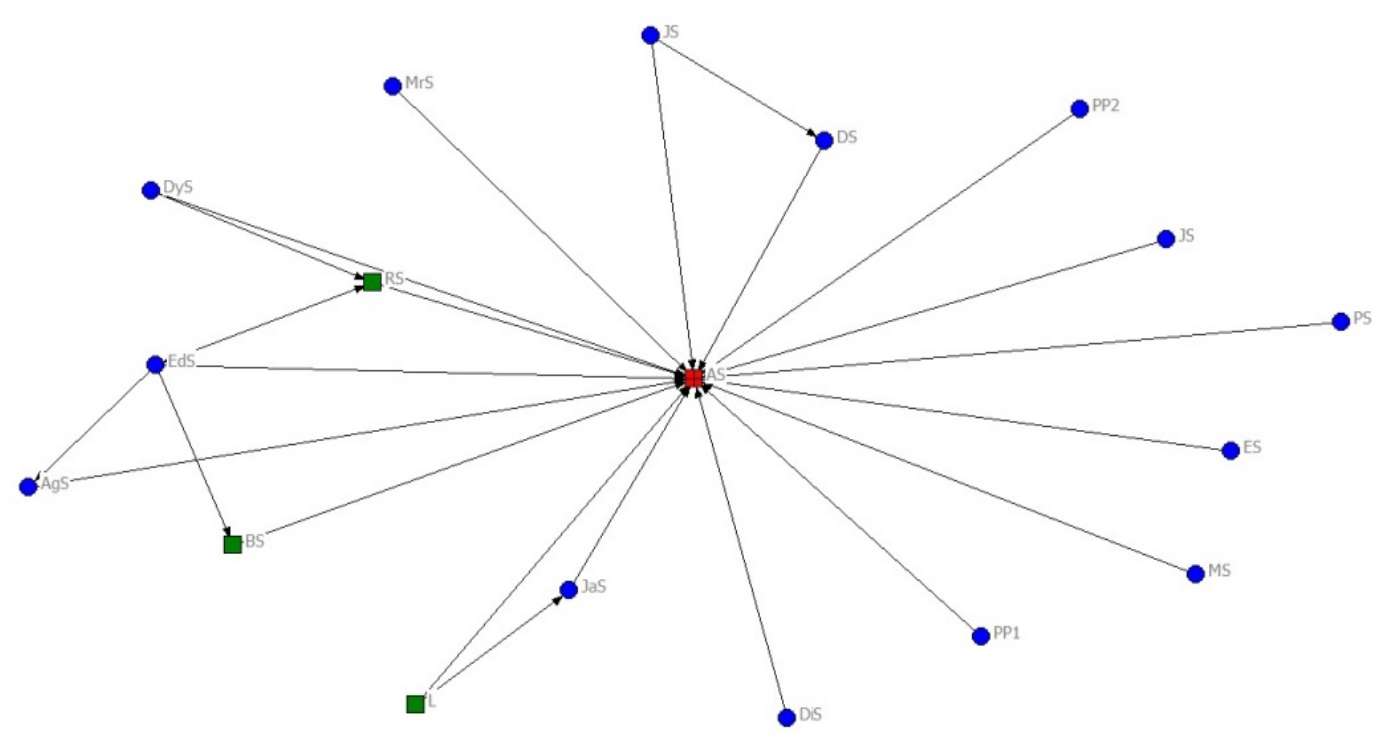

Source: The results of the interview data in October 2017, the data is processed using the Ucinet program

Figure 1: Mapping of AS Group Social Networks (Rohakinian)

From the results of the sociogram mapping above, it can be seen the number of links formed between ego actors and alter actors and alter actors with alter actors as many as 22 ties. There are 17 ties that are formed between ego actors and alternative actorsAgS, EdS, RS, DyS, MrS, JS, DS, PP2, JS, PS, ES, MS, PP1, D6, $\mathrm{JaS}, \mathrm{L}, \mathrm{BS}$. And there are 5 ties that are formed between alter actors with alter actors (fellow farmers), namely JS-DS, DyS-RS, RS-EdS, EdS-AgS, EdS-BS, and L-JaS.

From the results of mapping the social network, the density of the ego actor is found on the alter actor, which is equal to 0.026 . The density of the AS group's social network did not reach number 1 , which meant that it kept away from network density. The largest density in the AS group was in JaS, AgS, DS, and JS, which was 0.500 , followed by RS, EdS, DyS and L with a density of 0.333 and the rest is not integrated density. In terms of distance and diameter there is no alter actor who contacts both the closest and the farthest distance in communicating with the ego actor. Each actor alter communicates directly to the ego actor.

According to Roger and Kincaid (Eriyanto, 2014) there are two network patterns in egocentric networks, namely network patterns interlocking (also called open networks), namely open networks with the intention of the ego with alters interacting, so that each network member contacts each other one another. Other network patterns are closed networks, which means that when interactions only occur between ego and alter and if there is interaction between alters, the cohesion of relations between alters is minimal or minimal. From the results of mapping social networks in AS groups, ego actors are connected to all alterations in groups and outside groups. The interactions between alter and alter cohesiveness are minimal. Interaction between alterations in this group includes: RS-EdS, AgS-EdS, JS -DS, JaS-L. There are four inter alterations that interact with each other in the results of network mapping. The little contact between alters makes low network cohesiveness in this Rohakinian social network. The low cohesiveness between alerts shows that the network pattern formed is a closed network pattern.

\section{Group Social Network Analysis IR (Siharo)}

As an ego actor IR has alter alter actors in egocentric social networks. The alter actors connected to it can be seen in the following network diagram:(figure 2) 


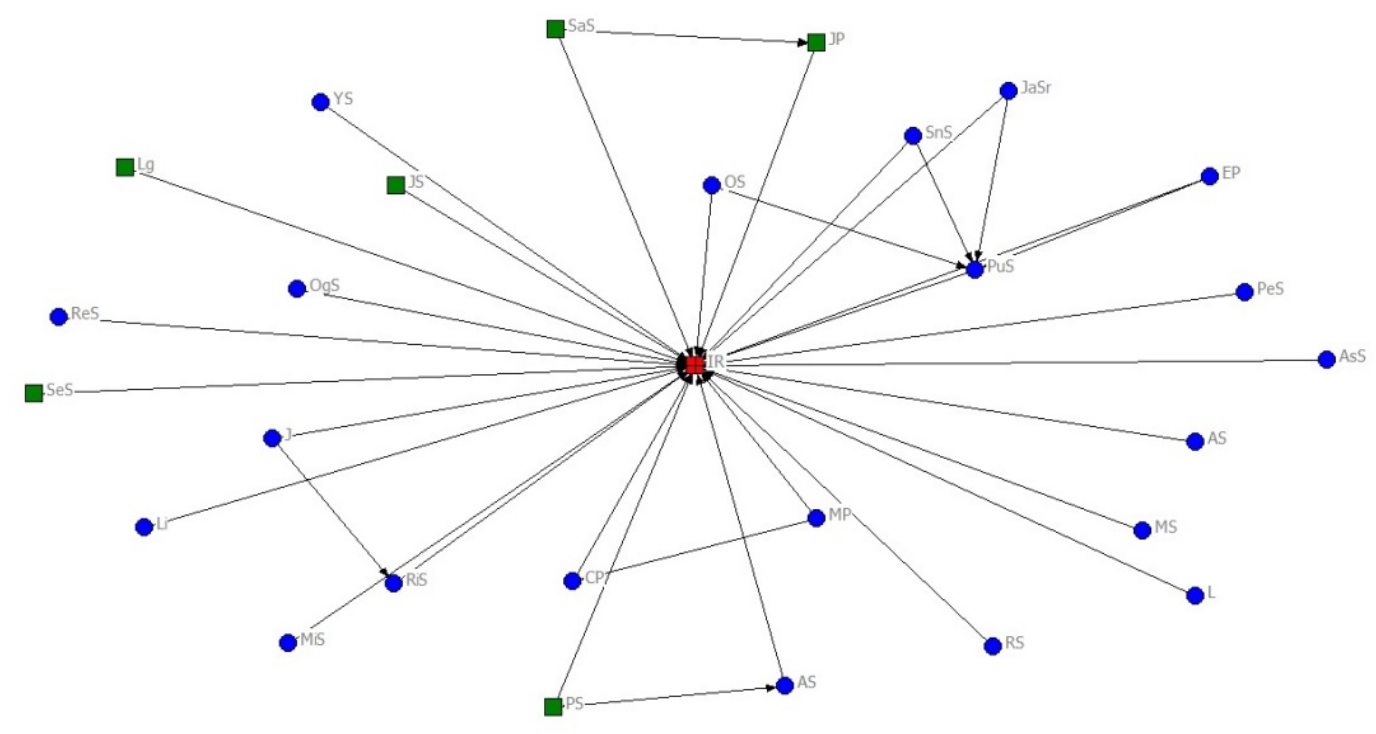

Source: The results of the interview data in October 2017, the data is processed using the Ucinet program

Figure 2: Mapping of Group Social Networks IR (Siharo)

From the results of the sociogram mapping above, it can be seen the number of links formed between ego actors and alter actors and alter actors with alter actors as many as 34 links. There are 27 ties formed between ego actors and alternative actors PS, CP, RS, MS, L, J, SeS, ReS, OgS, Lg, JS, YS, SaS, OS, JP, SnS, JaSr, PuS, EP, PES, ASS, US, MS, L, RS, MP, and US. And there are 7 ties that are formed between alter actors with alter actors (fellow farmers), namely RS-J, SaS-JP, OS -PuS, SnS-PUS, JaSr-PuS, CP-MP, and PS-AS.

Outside farmers who establish social relationships when fish do not always sell them to IR ego actors. There are a number of things that lead them to sell their fish harvest to this ego actor, that is, the payment process is more often in cash. Ego actor make payments to farmers outside the group in cash when the fish are packed and the amount of weight is known then the ego pays directly to the farmer without waiting for the fish to be in the hands of the retailer. From the results of the mapping of social networks the density is 0.014 , which means that the density of the social network of the Irwan Rajagukguk group does not reach 1, which means that it is far from network density. In terms of distance and diameter not an alter actor contacted the closest and farthest distance in contacting the ego actor. Each alter actor directly contacts the ego actor. Alter actors contact each other to tell actors who can help capitalize on their cage business.

The results of mapping the network, the interactions that occur between the actors in the Irwan Rajagukguk social network are seven links, namely J-RS, SaS-JP, OS -PuS, SnS-PUS, JaSr-PuS, CP-MP, and PS-AS. The seven ties / alterations between alters in the Siharo social network form an open network pattern caused by the slight cohesiveness between alters, more alters which are not connected to each other when compared to those that are interconnected.

\section{Analysis of the Paimaham Group Social Network}

In its business, BS integrates with a number of fellow farmers, both those who are capitalized and not, farmers in their groups and outside their groups. These farmers form social networks with BS. Social networks among 
these actors can be mapped in network diagrams. As for alter actors connected to them, they can be seen in the following network diagram:(figure 3)

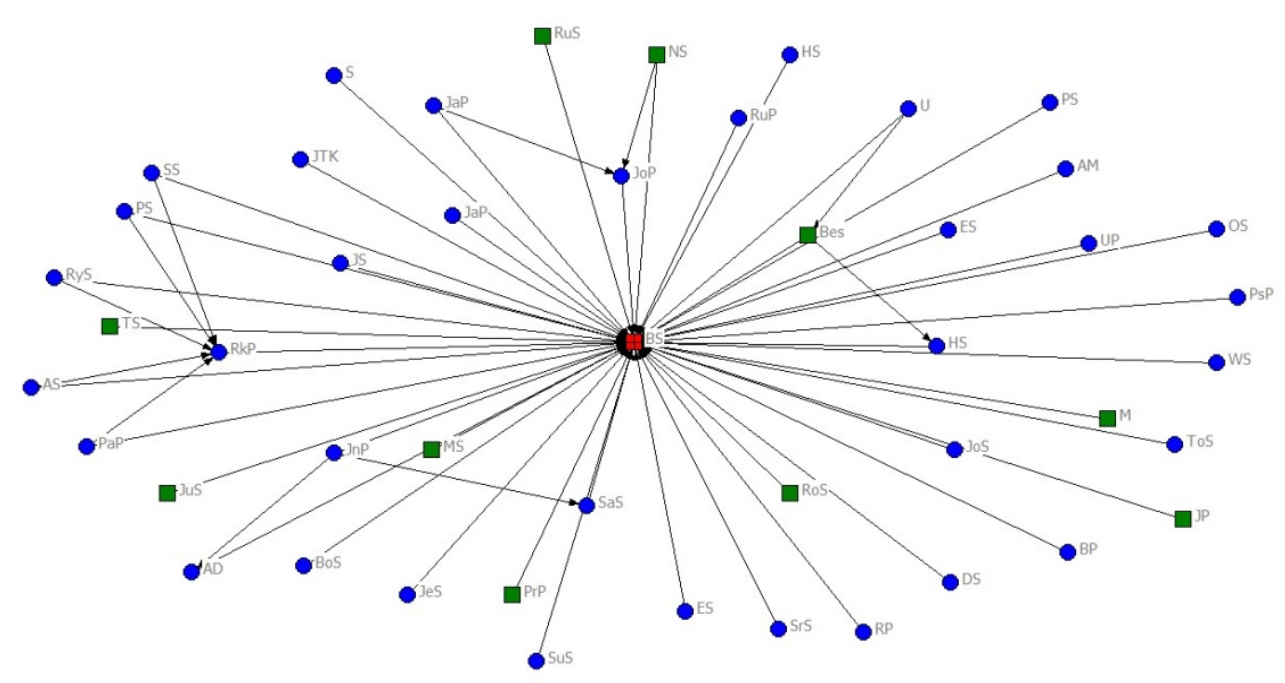

Source: The results of the interview data in October 2017, the data is processed using the Ucinet program.

Figure 3: Mapping the BS (Paimaham) Group Social Network

From the results of the sociogram mapping above, it can be seen the number of links formed between ego actors and alter actors and alter actors with alter actors as many as 57 links. There are 46 ties that are formed between ego actors and alternative actors namely JTK, JaP, S, JaP, RuS, JoP, NS, RuP, HS, U, Bes, PS, AM, ES, UP, OS, PSP, HS, WS, M , ToS, JoS, JP, BP, DS, RoS, Srs, ES, SaS, SuS, PrP, JeS, BoS, MS, AD, JnP, JuS, PaP, US, RkP, TS, RyS, PS, JS , SS. And there are 11 bonds / links formed between alter actors with alter actors (fellow farmers), namely JaP -JoP, NS-JoP, U-Bes, Bes -HS, JnP-SaS,, JnP- AD, PaP-RkP, USA - RkP, RyS-RkP, PS-RkP, SS-RkP. From the results of mapping the social network density of 0.005 which means that the density of the social network of Bombom Haloho's group did not reach 1 , which meant that it was very far from network density. In terms of diameter, Paimahamsama's social networks, such as the Rohakinian and Siharo networks, where no actor contacted each other both the closest and the furthest distance in contacting the host. Each alter actor directly contacts the ego actor, while alter who is integrated with other alters also directly contacts the ego in marketing the fish harvest without other alter actors. From the results of mapping social networks in BS groups, ego actors are connected to all alterations in groups and outside groups. While the interactions that occur between alter and alter cohesiveness are minimal. From the results of mapping the network, the network pattern is a closed network pattern. This can be seen from the integration between fellow practitioners in the Paimaham social network.

\section{Inter-Actor Social Relations}

The establishment of social interaction among actors in floating net cages in the Haranggaol area is inseparable from the social relations between the actors concerned. These relationships ultimately form a social network between them in carrying out their activities in marketing the results. fish harvest. The social network of this activity is centered on actors who are so important in floating net cage activities. By knowing who the main actor is contacted through the interactions of social relations among other actors, this social network is called the social network ego. Collectors (entrepreneurs / farmers owning capital) as ego actors have alter-alters (fish farmers) as their network to run their cage businesses. 
Finding information is important for prospective farmers to know the rules that apply and often also find out the strengths and weaknesses of the ego actor's character. After getting relevant information about the ego actor, the prospective farmer will go to the ego actor to ask for help in running a floating net cage business. However, even though the prospective farmers who still want to join have already obtained information from other fellow cage farmers, it does not necessarily make the ego actor immediately approve the wishes of prospective farmers to be helped to be financed. Egoism actors provide agreements that must be agreed upon by both parties, ego actors (collector traders / capital owners) and other actors (cage farmers).

The things that make the collector (entrepreneur / farmer the owner of capital) in choosing candidates for alterations to the cage farmers who want to join him are that he knows kinship or at least knows the identity of prospective cage farmers who want to open a floating net business. The family ties make it easier for them to collaborate in the cage business network. Meanwhile, those who do not have close family ties will ask for help from one of the cage farmers who have the family ties to join or be assisted in terms of capital of the prospective farmer cage.

The main reason why you have to have family ties is because this business is based on a sense of trust without any agreement in written form especially those charged with stamp duty. But that does not mean that the absence of the written agreement has no verbal agreement between them. Collaboration that forms the social network of cages among them also has oral agreements. Oral, which is generally known by prospective cage farmers before joining. Every collector / farmer who owns capital has the same agreement with each other. There is no agreement that is too significant even though one of them is for prospective cage farmers who want to open a cage business must buy fish seeds, fish feed and sell their fish to the cage farmers who provide capital / collectors.

While the relationship that exists between fellow cage farmers in addition to relationships that are familial but also because they already know each other. The relationship has been built because they are in the same hamlet or because they often gather in coffee shops, stalls that are often visited by Haranggaol residents to just tell stories or play cards. The intensity to meet in a shop makes those who gather in this place know each other.

\section{Implications of the Study}

As expressed by Granovetter in (Ritzer \& Goodman, Teori Sosiologi Modern, 2008) that relationships occur based on ideas, that actors (individuals or collectivities) are at different stratifications so that they have different access to valuable resources (wealth, power, information). These bonds will produce interconnected network nodes.

In this case, access for ego actors in marketing fish yields is more limited (broad), whereas alter actors especially those who are outside the ego group are limited in terms of marketing fish products. In accessing capital, alter actors who are limited to fulfilling all capital whose numbers are not small in floating net can work together with ego actors so that their business continues. Collaboration is the result of communication from the actors for the information obtained. Information obtained is information from close relatives including family, friends and friends or hamlet friends.

Furthermore, (Lawang, 2004) mentions social networks (social networks) is a social structure created by individuals or organizations commonly called nodes that are bound or connected by one or more certain interdependent characteristics between them. Some examples of social networks include friendship, kinship, financial exchange, relationships of dislike, sexual relations or relationships of trust, knowledge or prestige.

For the ego actor, to make his business run and produce as desired, the ego actor gives confidence to the alter actor in borrowing capital for the fish cage business which will continue to sell the harvested fish. This is evidenced by the many alter actors who are part of families both close and distant families who still live in Haranggaol. With alter actors who are a family of ego actors, trust in running a cage business will continue to remain intact. 


\section{Conclusion}

The creation of a social network among ego and alter actors is due to their need to market the results of their cages. Cage farmers need collectors (entrepreneurs / capital owners) to build cage businesses, get seeds and market their cage crops. Whereas the traders (entrepreneurs / capital owners) build networks with cages to meet the supply of cage harvests that they will market. Communication between alters and alter or alter and ego helps actors to exchange information about the process of cage cultivation and the marketing of cage products. The existence of family relationships and friendships based on the belief in creating a social network between actor ego and alter becomes more lasting. The social network formed between these actors is an egocentric social network centered on ego actors and alter actors. This social networks are the main keys to being able to help farmers (alter) in marketing / selling their harvested fish. Therefore, meetings are needed so that the intimacy of the actors becomes more intense and organizes related activities to advance the marketing system that mutually benefits both parties. Because basically this social network is intertwined because of the kinship relationship that is interconnected and thick friendship makes it difficult for migrants to run a cage business. Therefore an organization was created that could help immigrants to shelter them to open a cage business.

\section{References}

Borgatti, Stephen, P., \& Li, X. (2009). On Social Network Analysis In A Supply Chain Context. Journal of Supply Chain Management, 45(2), 5- 22. doi: https://doi.org/10.1111/j.1745-493X.2009.03166.x

Eriyanto. (2014). Analisis Jaringan Komunikasi: Strategi Baru Dalam Penelitian IImu Komunikasi dan IImu Sosial Lainnya. Jakarta: Kencana.

Field, J. (2005). Modal Sosial. Medan: Bina Medan Perintis.

Lawang, R. M. (2004). Kapita Soial Dalam Perspektif Sosiologi: Suatu Pengantar. Depok: FISIP UI Press. Retrieved from http://ucs.sulsellib.net//index.php?p=show_detail\&id=18786

Rachmawati, L., Mursinto, D., \& Istifadah, N. (2017). Fishery's Potential in Indonesia. International Journal if Humanities and Social Science Invention, 6(2), 58-64.

Rismawati. (2010). Analisis Daya Dukung Perairan Danau Toba Terhadap Kegiatan Perikanan Sebagai Dasar Dalam Pengendalian Pencemaran Keramba Jaring Apung. Medan: Sekolah Pascasarjana Universitas Sumatera Utara.

Ritzer, G., \& Goodman, D. J. (2008). Teori Sosiologi Modern. Jakarta: Kencana.

Stevens, K., Frank, K. A., \& Kramer, D. B. (2015). Do Social Networks Influence Small-Scale Fishermen's Enforcement of Sea Tenure? PLOS One, 1-17. doi:10.1371/journal.pone.0121431

Triyanti, R., Yuliaty, C., \& Apriliani, T. (2014). Peran Jaringan Sosial Nelayan Pada Pemasaran Tuna, Cakalang dan Tongkol: Studi Kasus di Kota Kendari. Jurnal Sosek KP, 9(2), 231- 219. doi:http://dx.doi.org/10.15578/jsekp.v9i2.1223

Turner, R. A., Polunin, N. V., \& Stead, S. M. (2014). Social Networks and Fishers Behavior: Exploring The Links Between Informaion Flow and Fishing Success in The Northumberland Lobster Fishery. Ecology and Society, 19(2), 38. doi:http://dx.doi.org/10.5751/ES-06456-190238 